\title{
Thermodynamic Studies of the Liquid Aluminum Alloy Systems*
}

\author{
By Akira Yazawa** and Yong Keun Lee***
}

\begin{abstract}
Thermodynamic properties of the liquid binary aluminum alloys have been investigated by various equilibrium measurements. The measurement of the electromotive force was carried out for the $\mathrm{Al}-\mathrm{In}, \mathrm{Al}-\mathrm{Sn}, \mathrm{Al}-\mathrm{Ga}$ and Al-Au systems using the following cells :
\end{abstract}

$\mathrm{Al}(\mathrm{l})\left|\mathrm{NaCl}+\mathrm{KCl}, \mathrm{AlCl}_{3}\right| \mathrm{Al}-\mathrm{Me}(\mathrm{l})$

For a part of the $\mathrm{Al}-\mathrm{Au}$ system, the distribution of gold between the $\mathrm{Pb}-\mathrm{Au}$ and $\mathrm{Al}-\mathrm{Au}$ phases was measured to obtain the activity of gold because the emf method was not suitable at temperatures higher than $1000^{\circ} \mathrm{C}$. The liquid $\mathrm{Al}-\mathrm{Zn}$ and $\mathrm{Al}-\mathrm{Te}$ systems were investigated by the dew point method which was improved so as to detect the dew point thermoanalytically.

The activities derived from the measured values show considerably positive deviations from Raoult's law for the Al-In, $\mathrm{Al}-\mathrm{Sn}$ and $\mathrm{Al}-\mathrm{Zn}$ systems, while in the Al-Ga system obey Raoult's law fairly well, and show negative deviations in the Al-Au and $\mathrm{Al}-\mathrm{Te}$ systems. The activity values thus obtained have compared with the previous data and those estimated theoretically in various ways. Moreover, activity coefficients at infinite dilution have also been calculated.

Other thermodynamic quantities of these systems have been derived from experimental data, and the limits of the miscibility gap in the Al-In system, which have not yet been established, was confirmed by the data on the electromotive force observed. (Received June 8, 1970)

\section{Introduction}

In connection with the alloy making, casting, refining and extractive metallurgy of aluminum, the thermodynamic behavior of various elements in liquid aluminum has become important, but only a limited number of the data has been available hitherto. Intending a systematic study on the thermodynamic properties of liquid aluminum alloy systems, the $\mathrm{Al}-\mathrm{In}, \mathrm{Al}-\mathrm{Sn}, \mathrm{Al}-\mathrm{Ga}$ and $\mathrm{Al}-\mathrm{Au}$ binary systems have been investigated by the electromotive force method, and the Al- $\mathrm{Zn}$ and $\mathrm{Al}-\mathrm{Te}$ systems have been studied by the improved dew point method. For a part of the Al-Au system, the distribution method has also been adopted because the application of the emf method was not convenient at temperatures higher than $1000^{\circ} \mathrm{C}$.

Among these systems, no data have been available for the activities of $\mathrm{Al}-\mathrm{In}, \mathrm{Al}-\mathrm{Ga}, \mathrm{Al}-\mathrm{Au}$ and $\mathrm{Al}-\mathrm{Te}$ systems, and for the Al-Sn system the experimental study was reported by Tihomirov et al.(1), which seems to be not so reliable. For the $\mathrm{Al}-\mathrm{Ag}^{(2)}, \mathrm{Al}-\mathrm{Cu}^{(3)}$ and $\mathrm{Al}-\mathrm{Ge}^{(4)}$ systems, thermodynamic studies were carried out by Wilder using the emf method. Considerable data are available for the $\mathrm{Al}-\mathrm{Zn}$ system, but judging from the reports by Hultgren et al. ${ }^{(5)}$ and Bolsaitis et al.(6), the previous measurements are not consistent with each other.

* This paper was published partly in Japanese in J. Japan Inst. Metals, 33 (1969), 318, 323.

** Research Institute of Mineral Dressing and Metallurgy, Tohoku University, Sendai, Japan.

*** Research Institute of Mineral Dressing and Metallurgy, Tohoku University, Sendai, Japan. Present address : Department of Metallurgy, College of Engineering, Chonpuk National University, Iri, Korea.

(1) A. A. Tihomirov, I. T. Sryvalin, O. A. Esin and B.M. Lepinskih : Tsvetnaja Metallurgija, No. 4 (1966), 23.

(2) T. C. Wilder and J. F. Elliott : J. Electrochem. Soc., 107 (1960), 628.

(3) T. C. Wilder : Trans. Met. Soc. AIME, 233 (1965), 1202.

\section{Experimental Method and Procedure}

The cells for the measurement of the electromotive forces are as follows :

$$
\mathrm{Al}(\mathrm{l})\left|\mathrm{NaCl}+\mathrm{KCl}, \mathrm{AlCl}_{3}\right| \mathrm{Al}-\mathrm{Me}(\mathrm{l})
$$

where, $\mathrm{Me}$ is $\mathrm{In}, \mathrm{Sn}, \mathrm{Ga}$ or $\mathrm{Au}$. The purities of all sample metals used in the experiment were more than $99.99 \mathrm{wt} \%$.

To prepare the electrolytes, guaranteed $\mathrm{NaCl}$ and $\mathrm{KCl}$ were first kept at $110^{\circ} \mathrm{C}$ and then at $350^{\circ} \mathrm{C}$ for $24 \mathrm{hr}$, respectively, in order to dry perfectly. About $5 \mathrm{wt} \%$ of aluminum chloride was added to the electrolyte. The electrodes of pure aluminum and alloys were prepared in high-purity alumina crucibles under vacuum; the lead wires of the electrodes were of tantalum wire.

The electrodes and electrolyte thus prepared were set in a silica reaction tube so as to construct a cell assembly as shown in Fig. 1, and then heated under vacuum to a given temperature. After introducing purified argon gas, the silica tube was held at a given temperature for 12 to $15 \mathrm{hr}$ until getting an equilibrium state in the reversible cell. The furnace temperature was controlled by a $\mathrm{Pt}-\mathrm{PtRh}$ thermocouple and a puls type PID controller within $\pm 1^{\circ} \mathrm{C}$. The electromotive forces have been measured by a potentiometer.

For each alloy, the electromotive forces were measured at intervals of $20^{\circ}$ to $30^{\circ} \mathrm{C}$, and to confirm the reproducibility of the data, the measurements were repeated several times at the same temperature. It took about $2 \mathrm{hr}$ after changing the measuring temperature to get a new equilibrium state in the cell, although it was

(4) T. C. Wilder : Trans. Met. Soc. AIME, 236 (1966), 88.

(5) R. Hultgren, R. L. Orr, D. Anderson and K. K. Kelley : Selecled Values of Thermodynamic Properites of Alloys, J. Wiley and Sons, (1963).

(6) P. Bolsaitis and P. M. Sullivan : Trans. Met. Soc. AIME, 245 (1969), 1435. 


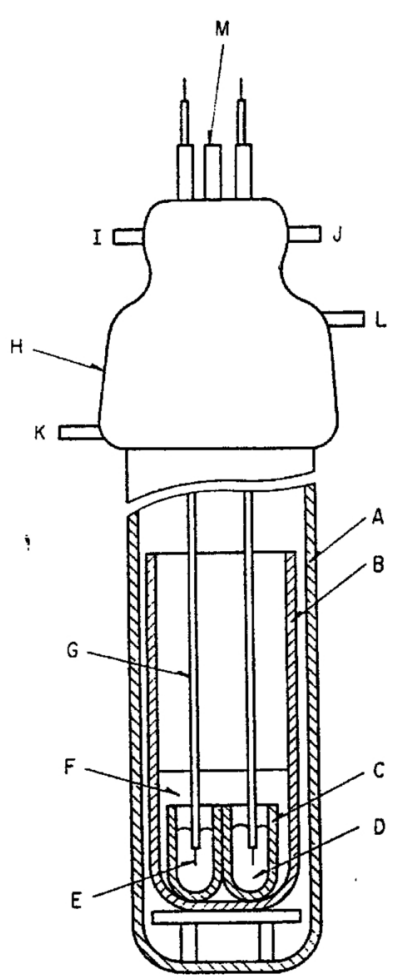

Fig. 1 Cell assembly.
$\mathrm{H}:$ Glass cap

I : Argon gas inlet

$\mathrm{J}:$ Argon gas outlet

$\mathrm{K}$ : Cooling water inlet

L : Cooling water outlet

M : Thermocouple inlet

E : Tantalum lead wire

F : Electrolyte

G : Alumina sheath

different depending upon the composition of alloy.

In the distribution method, 15 to $20 \mathrm{~g}$ of the sample consisted of aluminum, gold and lead was taken in the high purity alumina crucible to be melted in the heating furnace. The sample was heated at $1100^{\circ} \mathrm{C}$ for four $\mathrm{hr}$ under a current of purified argon gas. After getting the equilibrium of distribution for $\mathrm{Au}$ between the $\mathrm{Al}-$ $\mathrm{Au}$ phase and the $\mathrm{Pb}-\mathrm{Au}$ phase, the molten sample was cooled rapidly. The sample was separated into two layers and each layer was analyzed chemically.

The $\mathrm{Al}-\mathrm{Zn}$ and $\mathrm{Al}-\mathrm{Te}$ systems have been investigated by the dew point method which was improved so as to find out the dew point thermoanalytically and record it automatically. Instead of observing the condensed metal through a peep hole of the furnace body, the change of heat accompanied by volatilization or condensation was detected by means of differential thermal analysis. The silica reaction tube used for the measurement is illustrated

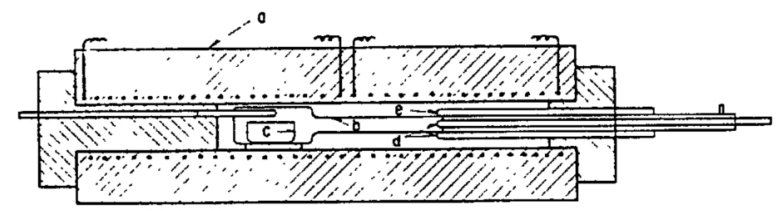

Fig. 2 Schematic diagram for thermoanalytic dew point apparatus. a : Electric furnace

b : Silica reaction tube

c : Alumina boat containing sample alloy

d : Thermocouple sheaths for differential thermal analysis

e : Thermocouple sheath for temperature observation

in Fig. 2. The alloy sample was taken in a high-purity alumina boat and sealed in the reaction tube with the boat under vacuum. Then the reaction tube was heated at a given temperature to be saturated with the metallic vapor. After getting the equilibrium state, the dew point portion of $\mathrm{d}$ and $\mathrm{e}$ in Fig. 2 was cooled gradually. When the vapor of zinc or tellurium started to condense as pure metal dew, the break point was observed on the recorded curve of differential thermal analysis. The dew point thus obtained under cooling and heating agreed within the difference of $1^{\circ} \mathrm{C}$.

\section{Results and Discussion}

\section{Aluminum-indium system}

It was confirmed in the preliminary experiment that the electromotive force was zero when both of the positive and negative electrodes were pure aluminum.

The relationships between the measured electromotive forces and temperatures for the $\mathrm{Al}-\mathrm{In}$ system are shown in Fig. 3. As shown in the figure, the electromotive forces are linear functions of temperature, and the coefficients of temperature dependence are positive. In the miscibility gap of the Al-In system, the values of electromotive forces remain unchanged with composition. At the limit of the miscibility gap for respective composition, the straight line of electromotive force represents a break point. Using these break points, the limits of miscibility gap which have not yet been established at above $800^{\circ} \mathrm{C}$ was determined as are illustrated in Fig. 4. The limits show the same general trend with those quoted by Hansen $(7)$, and the critical point locates at $878^{\circ} \mathrm{C}$ and 0.72 mole fraction of aluminum.

The partial molar quantities of aluminum have been derived using the values of electromotive force as follows:

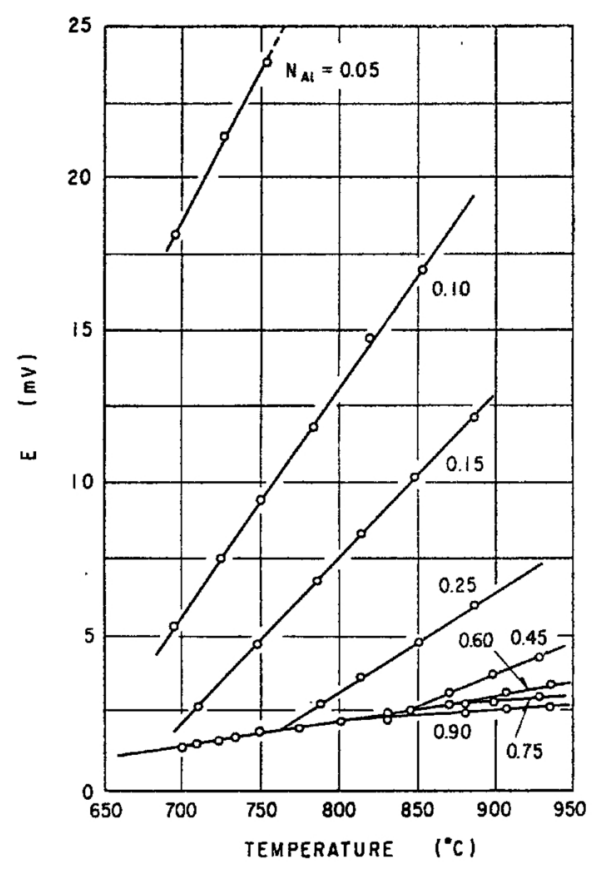

Fig. 3 Plots of emf values against temperature.

(7) M. Hansen and K. Anderko : Constitution of Binary Alloys, 2nd ed., McGraw-Hill, (1958). 


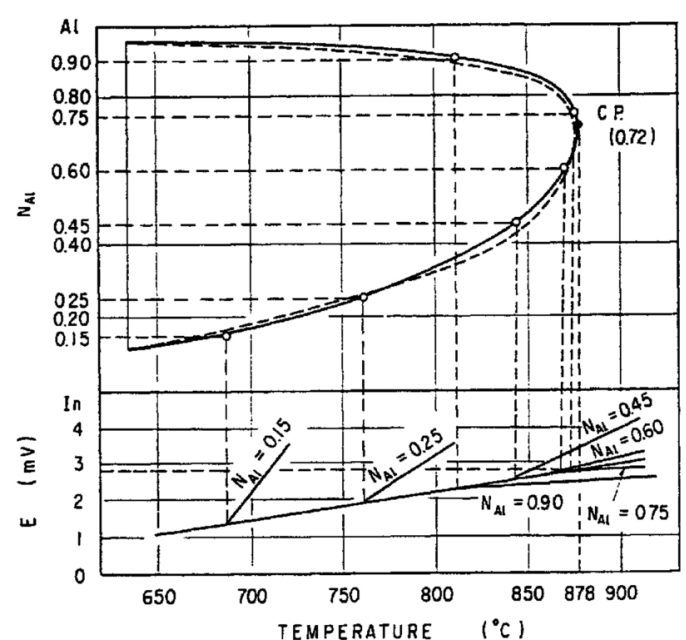

Fig. 4 Determination of miscibility gap based upon experimental results. Dashed line shows the miscibility gap quoted from Hansen.

$$
\begin{aligned}
& \Delta \bar{G}_{\mathrm{Al}}=R T \ln a_{\mathrm{Al}}=-n F E \\
& \Delta \bar{H}_{\Delta 1}=-n F\left[E-T(\partial E / \partial T)_{\mathrm{N} . \mathrm{P} .}\right] \\
& \Delta \bar{S}_{\mathrm{Al}}=n F(\partial E / \partial T)_{\mathrm{N} . \mathrm{P} .}
\end{aligned}
$$

It has been confirmed by Wilder ${ }^{(2) \sim(4)}$ that the value of the $n$ is 3 in liquid aluminum alloy systems, and no inconsistency could also be found in the present study for this number.

The partial quantities of indium have been derived by the Gibbs-Duhem equation, and the integral quantities also calculated.

Fig. 5 shows the activity curves in the $\mathrm{Al}-\mathrm{In}$ system at $700^{\circ}$ and $920^{\circ} \mathrm{C}$. The large positive deviation from Raoult's law and the horizontal activity lines in the miscibility gap are quite reasonable judging from the phase diagram.

Because no available activity data have been reported for the Al-In system, the activities have been calculated theoretically. The results derived from the liquidus of the phase diagram under the assumption of regular solution are shown in Fig. 5 with dash and dot lines,

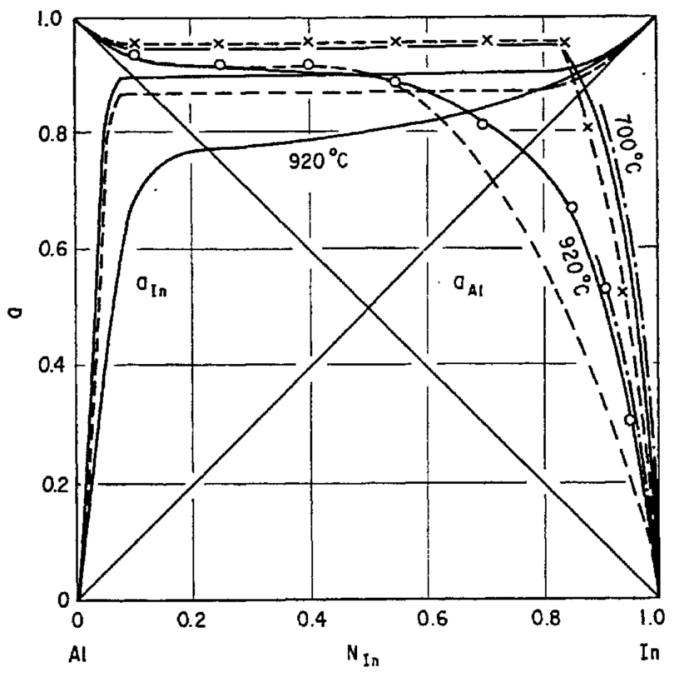

Fig. 5 Activity curves in the liquid Al-In system.

- Obtained in this work

---- Calculated by Lumsden model

-.- Calculated from liquidus line illustrating rather good agreement with those derived from the experiment.

Sundquist ${ }^{(8)}$ has confirmed that the Lumsden model ${ }^{(9)}$ derived from the statistical thermodynamics can supply the excellent results for obtaining the free energy of mixing from miscibility gap data. For simplifying the calculation, Lumsden's equation have been modified as follows :

$$
\Delta G^{\mathrm{xs}}=N_{\mathrm{B}}\left[\frac{\alpha}{1+m b^{2}}+\frac{\beta}{1+m b^{5}}-\frac{m b^{2} \alpha^{2}}{Z R T\left(1+m b^{8 / 3}\right)^{3}}\right]
$$

$R T \ln \gamma_{\mathrm{B}}=\frac{\alpha}{\left(1+m b^{2}\right)^{2}}+\frac{\beta}{\left(1+m b^{5}\right)^{2}}-\frac{m b^{2} \alpha^{2}\left(2-m b^{8 / 3}\right)}{Z R T\left(1+m b^{8 / 3}\right)^{4}}$

$$
\begin{aligned}
& R T \ln \gamma_{\mathrm{A}}=m^{2} b^{2}\left[\frac{\alpha}{\left(1+m b^{2}\right)^{2}}+\frac{\beta}{\left(1+m b^{5}\right)^{2}}\right. \\
& \left.-\frac{\alpha^{2}\left(2 m b^{8 / 3}-1\right)}{Z R T\left(1+m b^{8 / 3}\right)^{4}}\right]
\end{aligned}
$$

where $m=N_{\mathrm{B}} / N_{\mathrm{A}}$ (the ratio of mole fractions) $b=r_{\mathrm{B}} / r_{\mathrm{A}}$ (the ratio of atomic radii)

The atomic radii of $\mathrm{Al}$ and In are 1.429 and $1.579^{(10)}$, respectively, and the coordination number $Z$ was assumed to be 10. Two parameters of $\alpha$ and $\beta$ for the Al-In system have been calculated using eqs. (5) and (6) combined with the miscibility gap data, as follows :

$$
\begin{aligned}
& \alpha=32590-30 T \\
& \beta=-26430+30 T
\end{aligned}
$$

The activities of $\mathrm{Al}$ and $\mathrm{In}$ at $700^{\circ} \mathrm{C}$ and $920^{\circ} \mathrm{C}$, which have been derived using these parameters, are shown in Fig. 5 with dashed lines. As shown in the figure, in the composition range of the miscibility gap, the experimental results show good agreement with the results derived from the Lumsden model, but in the composition range rich in indium, the regular solution model is more consistent. This fact can be also understood from the $\alpha$-function of $\mathrm{Al}$ in the $\mathrm{Al}-\mathrm{In}$ system illustrated in Fig. 6 , and it is natural that the results derived from the experiment are agreeable with those from the Lumsden model in the miscibility gap range because the parameters $\alpha$

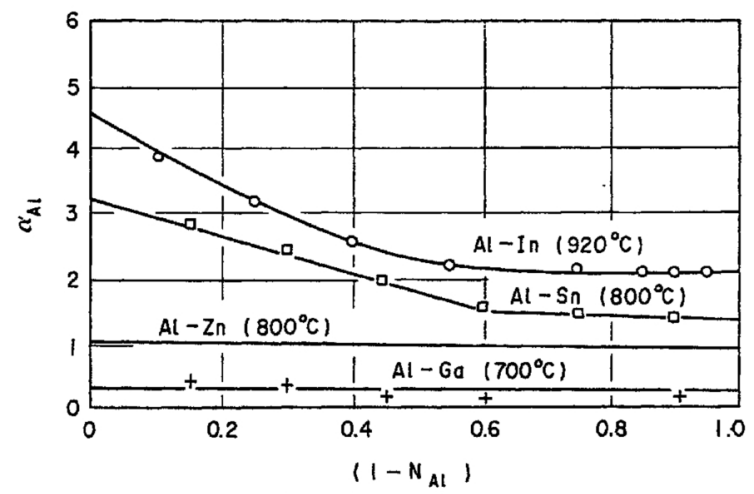

Fig. $6 \alpha$-function of $\mathrm{Al}$ for liquid aluminum binary systems.

(8) B. R. Sundquist : Trans. Met. Soc. AIME, 236 (1966), 1112.

(9) J.Lumsden : Thermodynamics of Alloys, The Institute of Metals, (1952), p. 322.

(10) L. Pauling : The Nature of the Chemical Bond, Cornell Univ. Press, Ithaca, (1960). 
and $\beta$ have been determined using the miscibility gap data.

Fig. 7 shows the partial and integral heats of mixing data at $800^{\circ} \mathrm{C}$ derived from the experimental values. In the miscibility gap range, the data are expressed with straight lines, but when the miscibility gap can be ignored, the integral heat of mixing would be shown with dashed line, which agree well with the data obtained by Wittig(11) with a high-temperature calorimeter. The positive values of the heats of mixing suggest the repulsive tendency between aluminum and indium atoms in this liquid system.

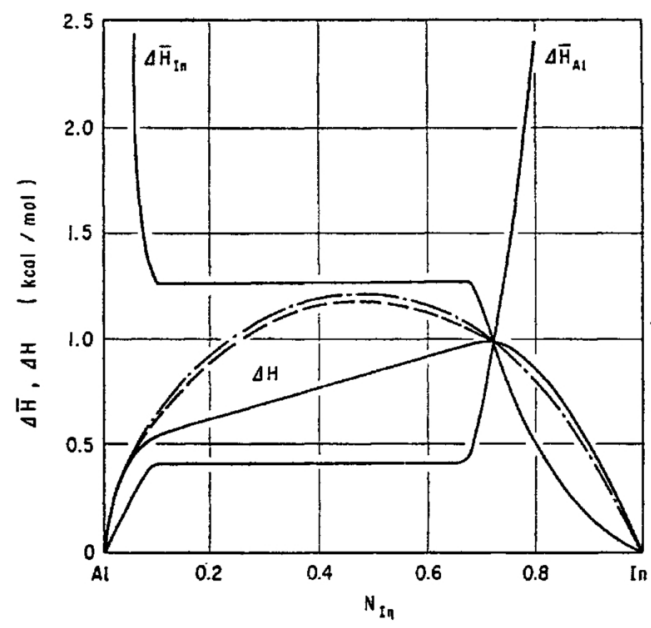

Fig. 7 Heats of mixing in molten Al-In alloy. This work at $800^{\circ} \mathrm{C}$

-.-- Extraporation into all miscible alloy -.- Result obtained by Wittig

\section{Aluminum-tin and aluminum-gallium systems}

The plots of the observed electromotive force values against temperatures for the liquid $\mathrm{Al}-\mathrm{Sn}$ and $\mathrm{Al}-\mathrm{Ga}$ systems are shown in Figs. 8 and 9. The activity curves derived from the experimental data are shown in Figs. 10 and 11 for the $\mathrm{Al}-\mathrm{Sn}$ system at $800^{\circ} \mathrm{C}$ and $\mathrm{Al}-\mathrm{Ga}$ system at $700^{\circ} \mathrm{C}$, respectively. Substantial positive deviations from the behavior of ideal solution are observed for the $\mathrm{Al}-\mathrm{S} n$ system, while the $\mathrm{Al}-\mathrm{Ga}$ liquid seems to be nearly ideal. Both of these systems are of simple eutectic type, and the activities of $\mathrm{Al}$ have been calculated from the liquidus of the phase diagrams. The calculated results shown with dashed lines in Figs. 10 and 11 agree well with the curves obtained from the experiments.

The results obtained by Tihomirov et al. ${ }^{(1)}$ are reproduced in Fig. 10 with the dash and dot line, suggesting large differences from those in the present study. They used tungsten as the lead wires of the electrode, which is dissolved in liquid aluminum, and this seems to be one of the error sources in their experiment.

In view of the values of the $\alpha$-function illustrated in Fig. 6, the Al-Ga liquid are considered as a regular solution which slightly deviates from Raoult's law, while the Al-Sn system shows the regular behavior only in the tin-rich range, and seems to show the behavior of

(11) F. E. Wittig and G. Keil : Z. Metallk., 54 (1963), 581.

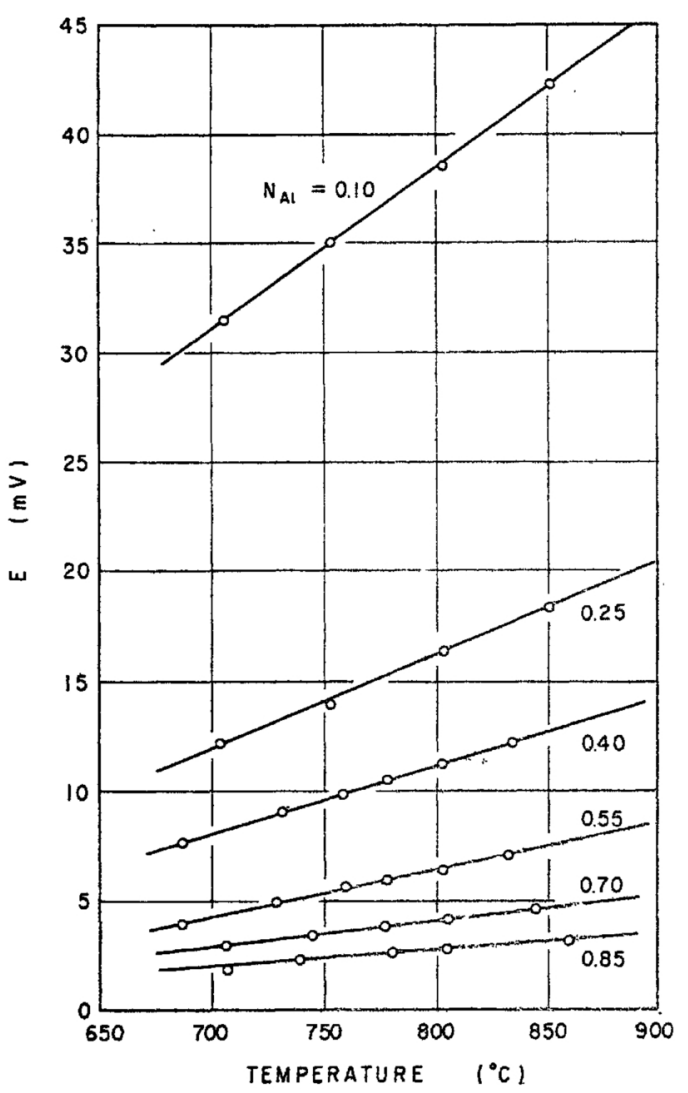

Fig. 8 Plots of emf values againsi temperatures for liquid AI-Sn alloys.

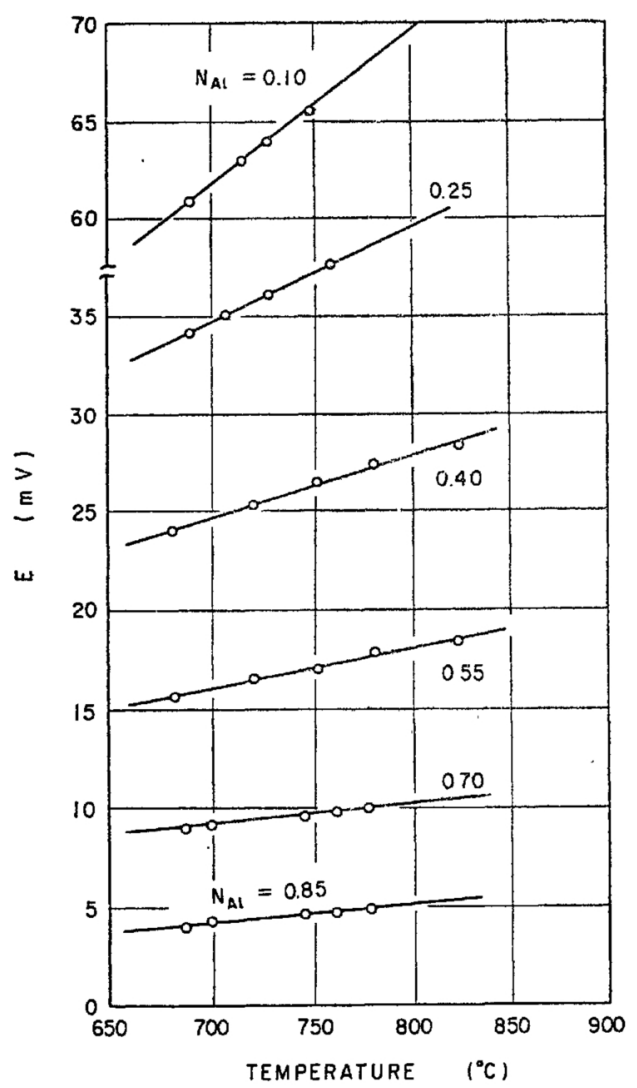

Fig. 9 Plots of emf values against temperature for liquid Al-Ga alloys. 
subregular solutions ${ }^{(12)}$ in the aluminum-rich range.

The activity coefficients at infinite dilution have been derived from the obtained results, and are summarized with the data on other systems in Table 1.

The excess quantities of mixing are summarized in Figs. 12 and 13 for the $\mathrm{Al}-\mathrm{Sn}$ system at $800^{\circ} \mathrm{C}$ and the Al-Ga system at $700^{\circ} \mathrm{C}$, respectively. The heat of mixing data obtained for the Al-Sn system agree well with those determined by $\mathbb{W}$ ittig ${ }^{(1)}$. From the fact that the values of $T \Delta S^{\text {ex }}$ for both systems are rather small but

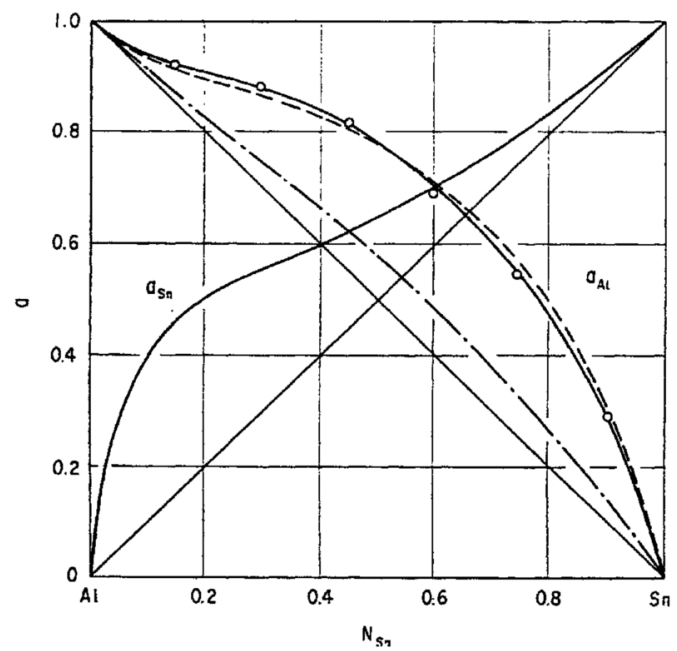

Fig. 10 Activity curves in the liquid Al-Sn system at $800^{\circ} \mathrm{C}$ - Obtained in this work

- Calculated from liquidus line -. - Obtained by Tihomirov et al.

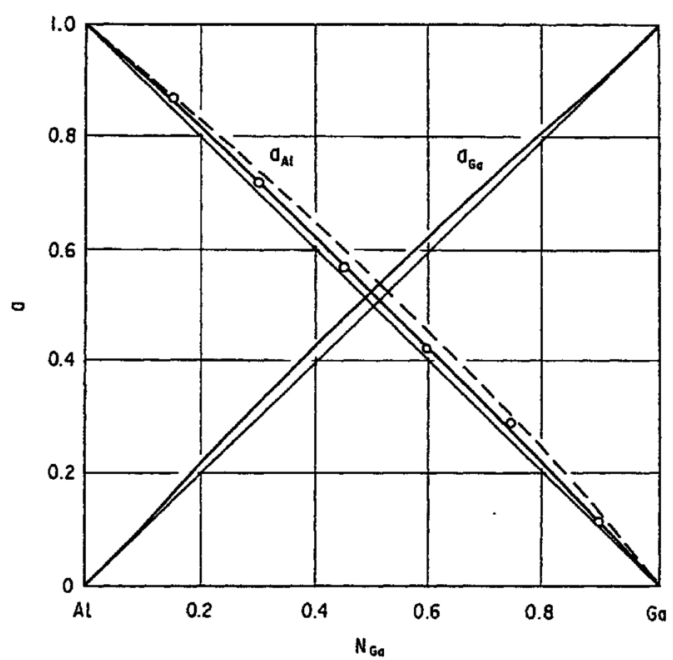

Fig. 11 Activity curves in the liquid Al-Ga system at $700^{\circ} \mathrm{C}$ Measured in this work

- Calculated from liquidus line

Table 1 Activity coefficients at infinite dilution

\begin{tabular}{l|c|c|c}
\hline System & $\begin{array}{c}\text { Temperature } \\
\left({ }^{\circ} \mathrm{C}\right)\end{array}$ & $\gamma_{\mathrm{Al}}^{0}$ & $r_{\text {Me }}^{0}$ \\
\hline Al-In & 700 & 11.5 & 13.2 \\
Al-Sn & 800 & 4.05 & 7.11 \\
Al-Ga & 700 & 1.15 & 1.27 \\
Al-Au & 1100 & 0.00013 & 0.0025 \\
Al-Zn & 800 & 2.79 & 2.80 \\
Al-Te & 900 & 0.14 & 0.29 \\
\hline
\end{tabular}

(12) H. K. Hardy : Acta Met., 1 (1953), 203.

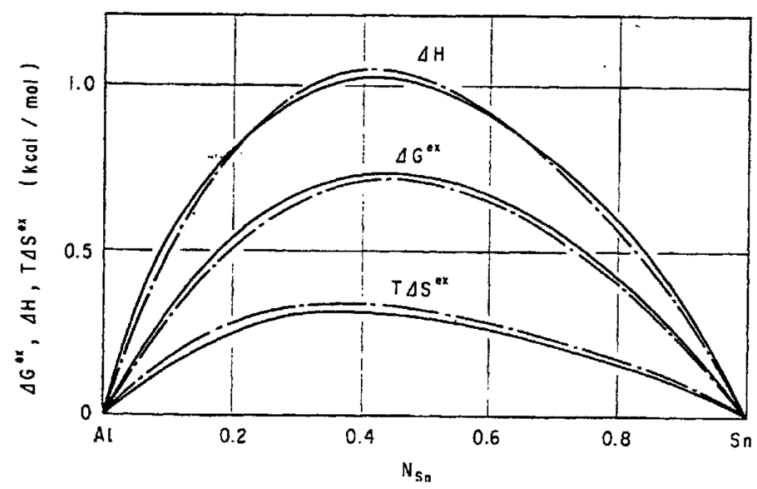

Fig. 12 Excess quantities of mixing in the liquid Al-Sn system at $800^{\circ} \mathrm{C}$.

Experimental values in this work

-.- Values calculated with model

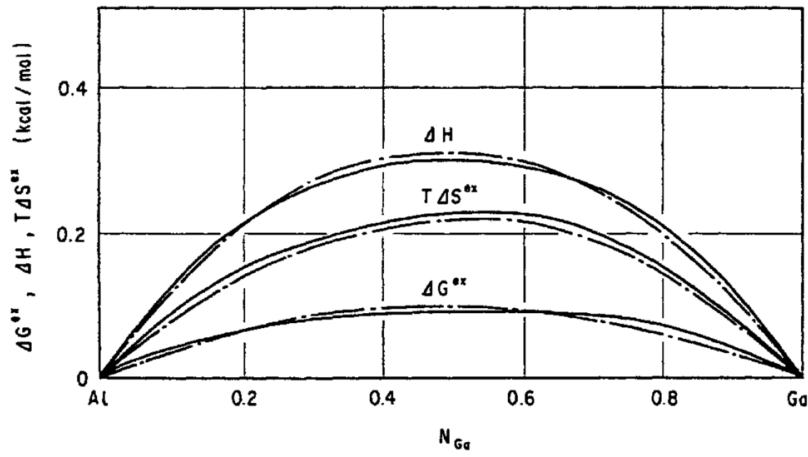

Fig. 13 Excess quantities of mixing in the liquid Al-Ga system at $700^{\circ} \mathrm{C}$.

- Experimental values in this work

-. Values calculated with model

not zero, these systems are assumed to be regular solution only approximately but not in a strict sense.

Based upon the statistical thermodynamics, Guggenheim ${ }^{(13)}$ proposed the following equations :

$$
\begin{aligned}
& \Delta H=N_{\mathrm{A}} N_{\mathrm{B}} \sum_{\nu=0.1} a_{\nu}\left(N_{\mathrm{A}}-N_{\mathrm{B}}\right)^{\nu} \\
& \Delta S^{\mathrm{xs}}=N_{\mathrm{A}} N_{\mathrm{B}} \sum_{\nu=0.1} b_{\nu}\left(N_{\mathrm{A}}-N_{\mathrm{B}}\right)^{\nu}
\end{aligned}
$$

When the value of $\nu$ are taken until 1 ,

$$
\begin{aligned}
& \Delta H=N_{\mathrm{A}} N_{\mathrm{B}}\left[a_{0}+a_{1}\left(N_{\mathrm{A}}-N_{\mathrm{B}}\right)\right] \\
& \Delta S^{\mathrm{xs}}=N_{\mathrm{A}} N_{\mathrm{B}}\left[b_{0}+b_{1}\left(N_{\mathrm{A}}-N_{\mathrm{B}}\right)\right]
\end{aligned}
$$

The coefficients $a_{0}, a_{1}, b_{0}$ and $b_{1}$ have been determined for the Al-Sn system as follows :

$$
\begin{array}{lc}
\Delta H=3550 N_{\mathrm{A} 1} N_{\mathrm{Sn}} & \left(N_{\mathrm{A} 1}<0.3\right) \\
\Delta S^{\mathrm{xs}}=1.0 N_{\mathrm{A} 1} N_{\mathrm{Sn}} & \left(N_{\mathrm{A} 1}<0.3\right) \\
\Delta H=N_{\mathrm{A} 1} N_{\mathrm{Sn}}[4050+1250 & \left.\left(N_{\mathrm{A} 1}-N_{\mathrm{Sn}}\right)\right] \\
\Delta S^{\mathrm{xs}}=N_{\mathrm{A} 1} N_{\mathrm{Sn}}[1.2+0.7 & \left(N_{\mathrm{A} 1}>0.3\right) \\
& \left(N_{\mathrm{A} 1}>0.3\right)
\end{array}
$$

Moreover, for the Al-Ga system,

$$
\begin{aligned}
& \Delta H=1267 N_{\mathrm{A} 1} N_{\mathrm{Ga}} \\
& \Delta S^{\mathrm{xs}}=0.93 N_{\mathrm{A} 1} N_{\mathrm{Ga}}
\end{aligned}
$$


The excess molar quantities illustrated in Figs. 12 and 13 are represented very well by these equations.

\section{Aluminum-gold system}

Fig. 14 shows the plots of the electromotive force values against temperature for the $\mathrm{Al}-\mathrm{Au}$ system. The linear temperature dependence is observed but the coefficients are negative, suggesting large negative deviations of activities from Raoult's law. The derived activity values of $\mathrm{Al}$ are plotted in Fig. 15 with the circles.

In the Al-Au system, however, the electromotive force method could not be applied for the composition range from 0.15 to 0.45 mole fraction of Au, because the melting point of the alloy in this range is too high, as is seen in the phase diagram ${ }^{(7)}$. The alloys in this range were studied by the distribution method. The melted

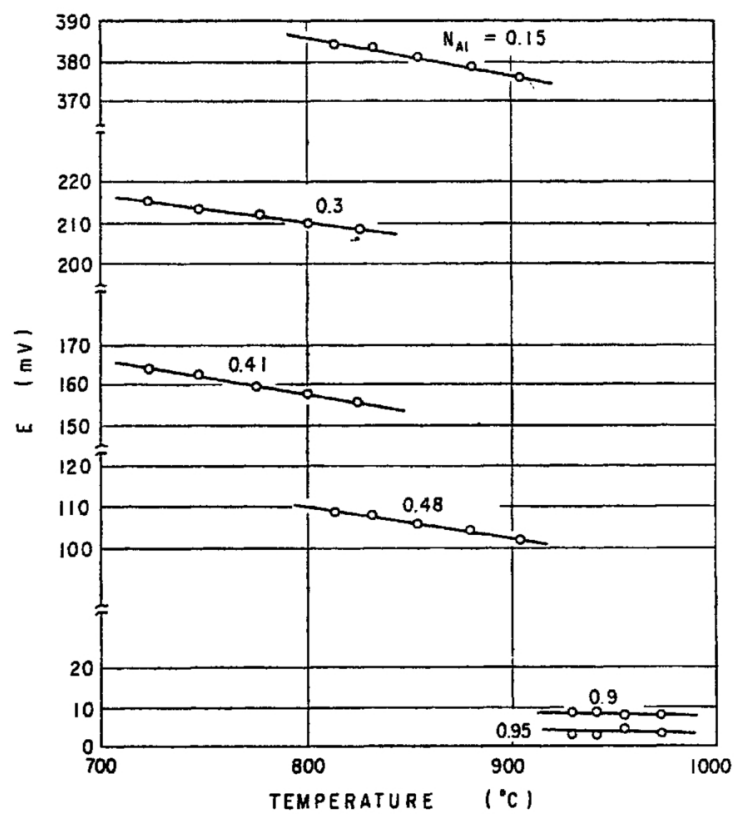

Fig. 14 Plots of emf values against temperature for liquid Al-Au alloys.

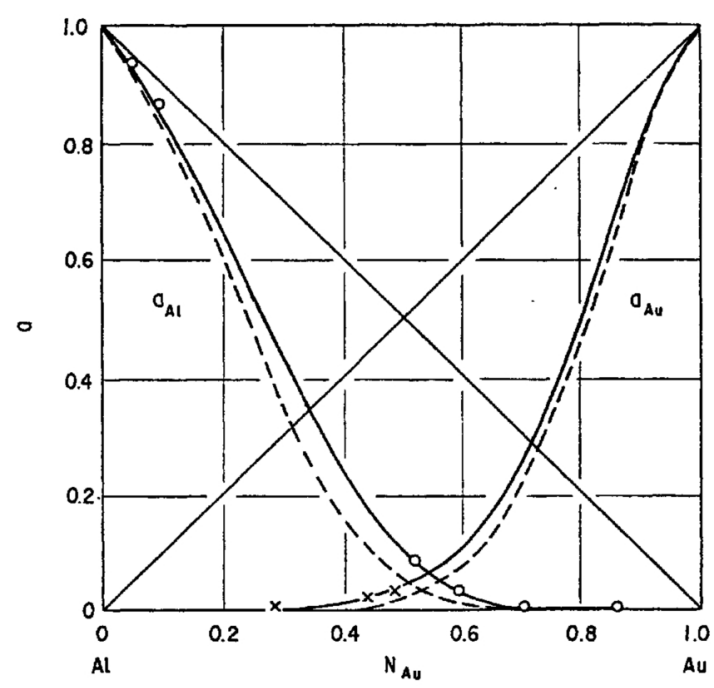

Fig. 15 Activity curves in the liquid Al-Au system at $1100^{\circ} \mathrm{C}$.

$O$ Values obtained by emf method

$\times$ Values obtained by distribution method

-.- Curves calculated from heats of fusion of $\mathrm{Au}_{2} \mathrm{Al}$ and $\mathrm{AuAl}_{2}$ sample consisted of two layers, one of which was rich in lead, and another rich in aluminum. The chemical compositions obtained for the respective layers are illustrated in Fig. 16. Undoubtedly the activities of $A u$ in both phases should have the same values:

$$
a_{\mathrm{Au}}(\mathrm{Al}-\mathrm{Au} \text { phase })=a_{\mathrm{Au}}(\mathrm{Pb}-\mathrm{Au} \text { phase })
$$

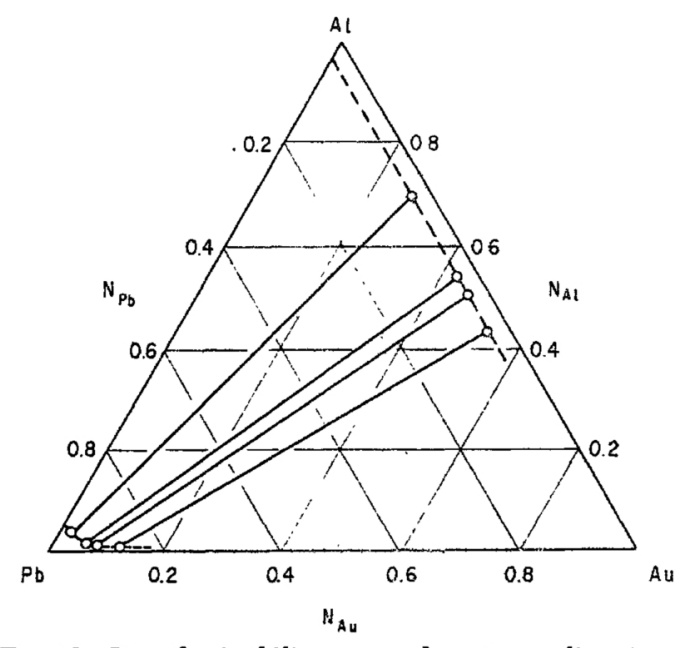

Fig. 16 Liquid miscibility gap and conjugate lines in the ternary Al-Pb-Au system.

Based upon Hultgren's data ${ }^{(5)}$, the activity coefficient for the $\mathrm{Pb}-\mathrm{Au}$ system in the composition range of 0 to 0.2 mole fraction of $\mathrm{Au}$ has been derived as follows :

$$
R T \ln \gamma_{\mathrm{Au}}=-2300\left(1-N_{\mathrm{Au}}\right)^{2}+200\left(1-N_{\mathrm{Au}}\right)^{3}
$$

Using this equation and the composition values of the respective layers, the activity data of $\mathrm{Au}$ for the $\mathrm{Al}-\mathrm{Au}$ system have been determined, and are plotted in Fig. 15 with a mark of cross.

Using the Gibbs-Duhem relation, the activity curves for both components were summarized and are shown in Fig. 15 with solid curves. These curves can be expressed approximately with the following equations :

$$
\begin{aligned}
& R T \ln \gamma_{\mathrm{Al}}=-8170\left(1-N_{\mathrm{Al}}\right)^{2}-16330\left(1-N_{\mathrm{Al}}\right)^{3}, \\
& R T \ln \gamma_{\mathrm{Au}}=-32660\left(1-N_{\mathrm{Au}}\right)^{2}+16330\left(1-N_{\mathrm{Au}}\right)^{3} .
\end{aligned}
$$

The activities show considerably negative deviations from Raoult's law, and the activity coefficients at infinite dilution are very small values as are shown in Table 1.

Burylev ${ }^{(14)}$ explained the method by which the activities are derived based upon the liquidus curves and heats of fusion of intermetallic compounds. In the equation for the systems 1 and 2 ,

$$
R T \ln \gamma_{2}=\left(Q^{\prime}+2 Q^{\prime \prime}\right) N_{1}^{2}-2 Q^{\prime \prime} N_{1}^{3}
$$

the parameters $Q^{\prime}$ and $Q^{\prime \prime}$ can be determined from the following equation which is valid at the melting point of the intermetallic compound.

$$
\left(\frac{d^{2} T}{d N_{2}^{2}}\right)_{\max } \Delta S_{f}=-\frac{R T}{N_{1} N_{2}}+2 Q^{\prime}-2 Q^{\prime \prime}+6 Q^{\prime \prime} N_{2} .
$$

(14) B. P. Burylev : Tsvetnaja Metallurgija, No. 4 (1967), 35. 
$\left(d^{2} T / d N_{2}^{2}\right)_{\max }$ is derived from the following liquidus curve equation :

$$
T=a+b\left(N_{2}-N_{2}^{\max }\right)^{2}+c\left(N_{2}-N_{2}^{\max }\right)^{3} .
$$

If the experimental data are not available for the heat of fusion of the intermetallic compound, entropy of fusion, $\Delta S_{f}$, can be estimated by the additive law. For the ordered compound, the entropy change from order to disorder, $-R\left(N_{1} \ln N_{1}+N_{2} \ln N_{2}\right)$, should also be added. Thus, based upon Kubaschewski's data ${ }^{(15)}$, the entropy of fusion for $\mathrm{AuAl}_{2}$ and $\mathrm{Au}_{2} \mathrm{Al}$ were derived to be 3.85 and $2.45 \mathrm{cal} / \mathrm{deg} \cdot$ atom, respectively. Using these values and liquidus curves adjacent to $\mathrm{AuAl}_{2}$ and $\mathrm{Au}_{2} \mathrm{Al}$, the following equations were derived from eqs. (21) to (23).

$$
\begin{aligned}
& R T \ln r_{\mathrm{Al}}=-15250 N_{\mathrm{Au}}^{2}-16440 N_{\mathrm{Au}}^{3}, \\
& R T \ln r_{\mathrm{Au}}=-39910 N_{\mathrm{Al}}^{2}+16440 N_{\mathrm{Al}}^{3} .
\end{aligned}
$$

The resulting activity curves at $1100^{\circ} \mathrm{C}$ are shown in Fig. 15 with dashed lines, illustrating slight discrepancies but the same trends with those from the experimental values.

Various partial and integral quantities have been calculated for the $\mathrm{Au}-\mathrm{Al}$ system, and the excess integral quantities are illustrated in Fig. 17.

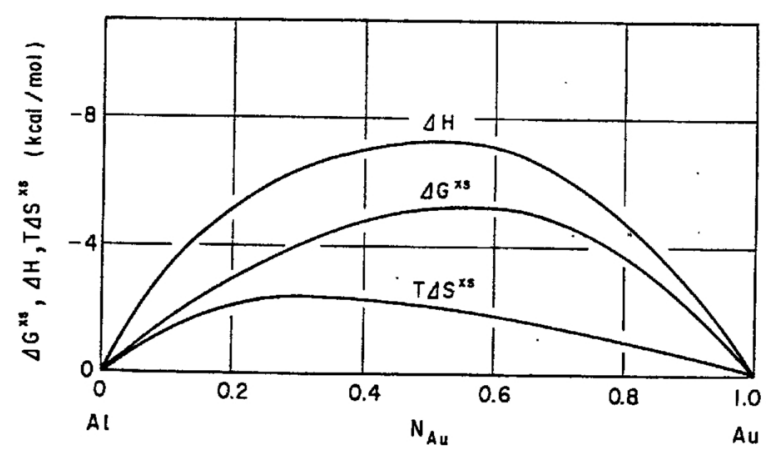

Fig. 17 Excess quantities of mixing in the liquid $\mathrm{Al}-\mathrm{Au}$ system at $1100^{\circ} \mathrm{C}$.

\section{Aluminum-zinc and aluminum- tellurium systems}

Activities of $\mathrm{Zn}_{\mathrm{n}}$ and $\mathrm{Te}$ were calculated from the following equations :

$$
\begin{aligned}
& a_{\mathrm{Zn}}=p_{\mathrm{Zn}} / p_{\mathrm{Zn}}^{0} \\
& a_{\mathrm{T \theta}}=\left(p_{\mathrm{Te}_{2}} / p_{\mathrm{Te}_{2}}^{0}\right)^{1 / 2}
\end{aligned}
$$

where $p_{\mathrm{Z}_{\mathrm{n}}}^{0}$ and $p_{\mathrm{T} \mathrm{e}_{2}}^{0}$ are the vapor pressures of pure zinc and tellurium, and calculated by the data of Kubaschewski et al. (14) $p_{\mathrm{zn}_{\mathrm{n}}}$ and $p_{\mathrm{Te}_{2}}$ show the vapor pressures over their alloys, respectively, and correspond to those of pure metals at the temperature of the dew point.

It has been reported ${ }^{(16)}$ that in the tellurium gas, consisting of the mixture of $\mathrm{Te}$ and $\mathrm{Te}_{2}$ pecies, the partial pressure of $\mathrm{Te}$ is very small as compared with that of $\mathrm{Te}_{2}$. Thus, in this work, the activities of tellurium

(15) O. Kubaschewski, E. LL. Evans and C.B. Alcock : Metallurgical Thermochemistry, Pergamon Press, (1967), p. 336.

(16) R. Hultgren, R. L. Orr and K. K. Kelley : Supplement to Selected Values of Thermodynamic Properties of Metals and Alloys, (1964), unpublished. have been calculated disregarding the vapor of monatomic species.

The activity curves obtained from the above equations and the Gibbs-Duhem equation are illustrated in Figs. 18 and 19. The activity curves in the Al-Zn system exhibit symmetrical and positive deviations from Raoultian behavior, and agree well with those obtained by Schneider et al. ${ }^{(17)}$, but show a substantial discrepancy from the data of other researchers as shown in Table 2. Because of the unreasonable temperature dependence of activity for this system, the data of Lutz et al. ${ }^{(18)}$ and Eremenko ${ }^{(19)}$ seem to be unreliable.

The $\alpha$-functions and the activity coefficients at infinite dilution are shown in Fig. 6 and Table 1, respectively. From the horizontal line of the $\alpha$ function, the regular solution assumption seems to be reasonable for the liquid $\mathrm{Al}-\mathrm{Zn}$ system, and the following equation agrees quite well with the experimental results.

$$
\log \gamma_{\mathrm{zn}}=0.45 N_{\mathrm{Al}}^{2}
$$

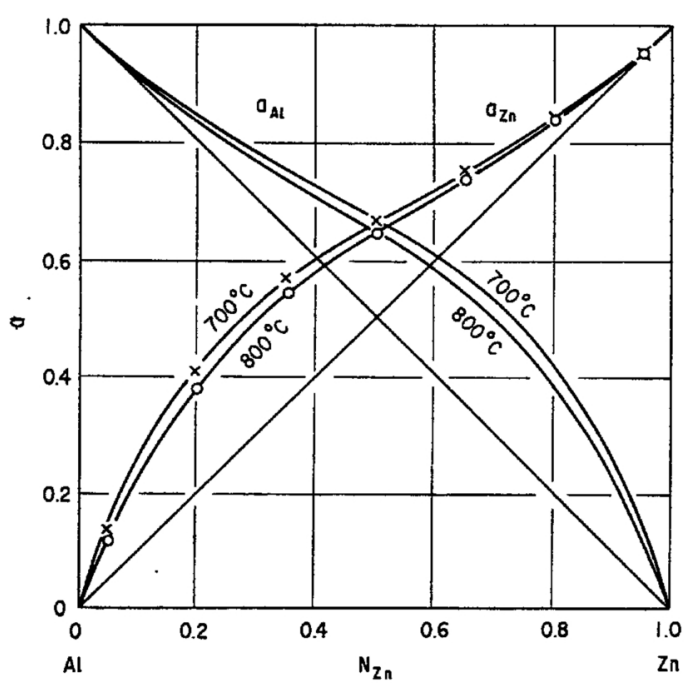

Fig. 18 Activity curves in the liquid Al-Zn system.

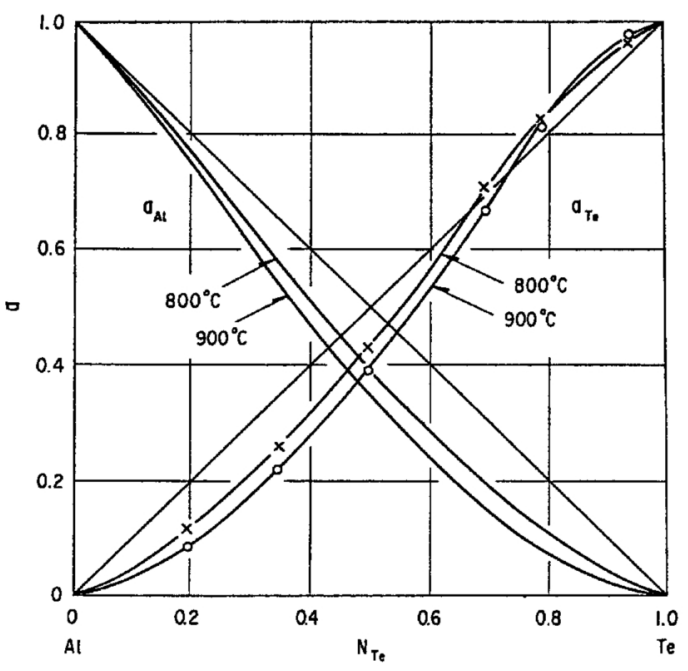

Fig. 19 Activity curves in the liquid A1-Te system.

(17) A. Schneider and E. K. Stoll : Z. Elektrochem., 47 (1941), 527.

(18) G. J. Lutz and A. F. Voigt : J. Phys. Chem., 67 (1963), 2795.

(19) V.N. Eremenko : Zh. Fiz. Khim. (USSR), 34 (1960), 1495. 
Table 2 Activity of zinc measured by various investigators

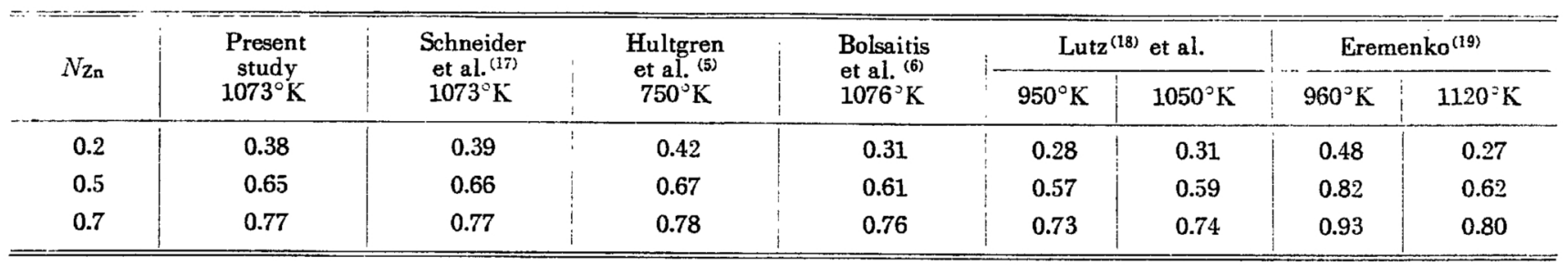

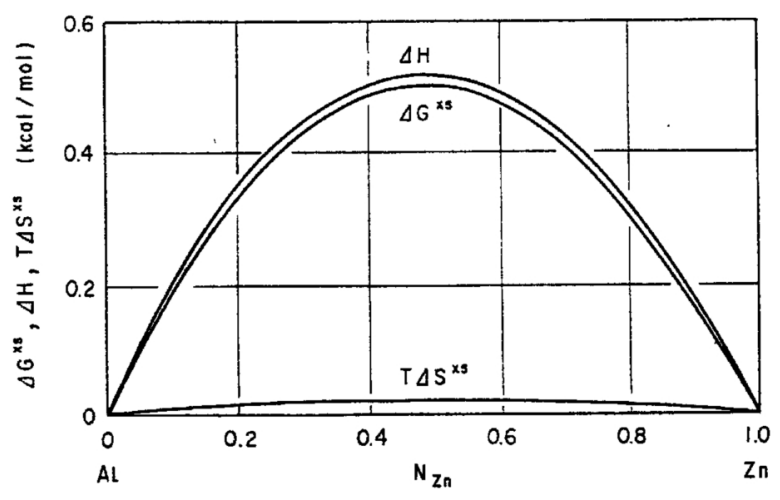

Fig. 20 Excess quantities of mixing in the liquid $\mathrm{Al}-\mathrm{Zn}$ system at $800^{\circ} \mathrm{C}$.

The regular solution behavior of the $\mathrm{Al}-\mathrm{Zn}$ system is also confirmed from the excess quantities illustrated in Fig. 20. The excess entropy of mixing is so small that the heat of mixing is nearly equal to the excess free energy of mixing.

Fig. 19 shows that the activities in the Al-Te system exhibit negative deviations from the ideal behavior on the whole, and the deviation increases with increasing temperature. Such a temperature dependence is opposite to the general trend of usual liquid alloy systems, suggesting the abnormal value of entropy of mixing, and is also observed in the systems including elements such as súlfur, antimony and arsenic which form stable intermetallic compounds and polymerized gaseous species.

\section{Summary}

To clarify the thermodynamic properties of the liquid aluminum alloys, the $\mathrm{Al}-\mathrm{In}, \mathrm{Al}-\mathrm{Sn}, \mathrm{Al}-\mathrm{Ga}$ and $\mathrm{Al}-\mathrm{Au}$ systems have been investigated by the electromotive force method, and the $\mathrm{Al}-\mathrm{Zn}$ and $\mathrm{AI}-\mathrm{Te}$ systems have been studied by the improved dew point method. For a part of the liquid Al-Au system the distribution method was also adopted.

The activities derived from measured values show considerably positive deviations from Raoult's law for the Al-In, Al-Sn and Al-Zn systems, while in the AlGa system obey Raoult's law fairly well, and show negative deviations in the $\mathrm{Al}-\mathrm{Au}$ and $\mathrm{Al}-\mathrm{Te}$ systems. The activity values thus obtained have been compared with the previous data and those estimated theoretically in various ways. Moreover, activity coefficients at infinite dilution have also been calculated.

Other thermodynamic quantities of these systems have been derived from experimental data, and the limit of the miscibility gap in the Al-In system, which has not yet been established, was confirmed by the data on electromotive force observed.

\section{Acknowledgment}

The authors wish to express their hearty appreciation to Assistant Prof. T. Azakami, Department of Metallurgy, Tohoku University, for his valuable suggestions given for the establishing of their experimental procedure. 